\title{
STRUCTURE OF INCIPIENTLY SOOTING PARTIALLY PREMIXED ETHYLENE COUNTERFLOW FLAMES
}

\author{
Francesco Carbone, Francesco Cattaneo, Alessandro Gomez \\ Yale Center for Combustion Studies, \\ Department of Mechanical Engineering and Materials Science, \\ Yale University, New Haven, CT 06520-8286, USA
}

Full-length article: submitted to Combustion and Flame on June 14, 2015

Revised on August 11, 2015

\footnotetext{
* Corresponding Author: Alessandro Gomez alessandro.gomez@yale.edu Tel: (203) 432-4384

Fax: (203) 432-7654
} 
We perturbed an atmospheric-pressure ethylene diffusion flame by progressively adding oxygen in the fuel stream, while holding constant peak temperature and stoichiometric mixture fraction. The resulting partially premixed flames presented a well-defined double-flame structure, with a (lightly) sooting region sandwiched between a premixed flame component and a diffusion flame one. Temperature measurements were performed using fine thermocouples and thin filament pyrometry, whereas species concentrations profiles of $\mathrm{CO}_{2}, \mathrm{CO}, \mathrm{N}_{2}, \mathrm{O}_{2}, \mathrm{H}_{2}$ and C1-C12 species, including aromatics, were determined by gas sampling through a quartz microprobe followed by GC-MS analysis. In addition to the diffusion flame, two of the flames, at equivalence ratio, $\Phi=6.5$ and $\Phi=5.0$, were probed in detail with these diagnostic techniques. A fourth flame at $\Phi=3.0$ was examined only qualitatively because of excessive soot presence. The premixed flame component of the dual flame structure and the diffusion flame one were coupled both thermally and chemically. Soot formation increases with lowering equivalence ratio and increasing temperature, a trend that is consistent with that of purely premixed strained flames stabilized against a hot nitrogen counterflow, as confirmed computationally by comparing profiles of a critical soot precursor such as benzene. However, partially premixed flames, probably as a result of the back diffusion of key radicals such as $\mathrm{H}$ and $\mathrm{OH}$ from the diffusion flame component, have a lower tendency to soot as compared to purely premixed ones. Comparison of measurements with computational results using two chemical kinetic mechanisms show good agreement for major species and, in one case, with some soot precursors such as benzene, despite mismatches in some critical intermediates. Reaction path analysis suggests an increasingly larger contribution of the C3 path to benzene formation with the lowering of the equivalence ratio. The database with the measurements of primary reactants, products and intermediates, including critical soot precursors up to 3-ring aromatics is available to developers of chemical reaction mechanisms.

Keywords: Partially Premixed Flame, Soot, Counterflow, Gas Sampling 


\section{Introduction}

Partially Premixed Flames (PPFs) are rich flames in which the fuel feed stream is premixed with some amount of oxidizer. If the equivalence ratio is above the rich flammability limit, the flame does not propagate; if it is below such a limit, it still retains its propagating capabilities. In either case the unburned fuel products can be further oxidized in a nonpremixed or diffusioncontrolled regime yielding a dual flame structure. These flames are of relevance to turbulent combustion in which, even if the fuel and oxidizer are originally separated at their injection in the combustion chamber, turbulence may engender some level of premixing with combustion taking place in a stratified medium [1-2], with a broad range of equivalence ratios from very rich to lean. This situation is relevant to gas turbine combustion and internal combustion engines, especially in the near-injector region. Even in nonpremixed turbulent combustion one can envision conditions of local extinction with a break in the flame surface, which will cause mixing of fuel and oxidixer, with ensuing partial premixing. Lastly, PPFs intervene in the stabilization of lifted turbulent flames via edge flames and, in some cases, triple flames consisting of a rich branch, a lean one, with a trailing diffusion flame fed by unburned CO and $\mathrm{H}_{2}$ from the premixed side [3].

In this study we examine PPFs in the soot context in the light of some work on compression ignition (CI) engines. Although such engines have been traditionally presented as a prototypical example of diffusion (nonpremixed) flame, the application of a variety of advanced laser diagnostics techniques challenged this concept [4]. The prevailing view is now that vaporization and mixing occur reasonably fast for the initial soot loading in the vicinity of the injector to be generated under rich premixed combustion [5]. Subsequently, soot grows and is oxidized across an envelope nonpremixed flame further downstream that is formed between the products of the rich premixed flame and the oxidizer. This scenario is very different from that typical of diffusion flames where soot is nucleated on the fuel side, under conditions of virtually infinitely large equivalence ratio. The simultaneous presence of oxidizing species with soot particulate affects the sooting process qualitatively and quantitatively by providing an opportunity for oxidation to act in parallel with soot formation [6]. As a result, a detailed understanding of soot formation in partially premixed flames is in order, especially under the high-pressure conditions that are typical of these engines.

The critical missing step in our understanding of soot formation is the inception (or nucleation) stage [7-12], where the transition from parent fuel gas molecule to soot nanoparticle occurs. To shed light on this step, a detailed chemical characterization of the flame is indispensable, which inevitably requires sampling followed by the application of analytical chemistry techniques. Engines are poorly suited to detailed probing. We chose instead well-controlled laminar flames in which the soot challenges can be decoupled from complications associated with turbulence and the presence of the droplet phase, without sacrificing the coupling of chemistry and transport.

With this in mind, we established a well controlled testbed consisting of a laminar counterflow with a rich mixture fed from one side, the oxidizer from the other and a mixed scenario of premixed-flame/diffusion flame in between, in what has been defined as two-stage combustion in one of the first studies of this type in counterflow [13]. This configuration is ideal to put in evidence the dual flame structure that had been observed in CI engines. It lends itself also to simple, mostly one-dimensional, computational modeling with well-specified boundary conditions, using detailed chemical kinetics, including soot precursors. 
As a first step towards the characterization of these flames under high-pressure conditions of relevance to engines, we focus here on atmospheric pressure $\mathrm{C}_{2} \mathrm{H}_{4} / \mathrm{O}_{2} / \mathrm{N}_{2}$ premixed streams counteflown to a $\mathrm{N}_{2} / \mathrm{O}_{2}$ stream, with equivalence ratios ranging from infinite (diffusion flame) to $\Phi=3$, under conditions of incipient or moderate sooting that are compatible with gas sampling by quartz microprobe. Sampling is followed by analysis with standard analytical chemistry techniques to quantify chemical growth to soot precursors such as polyaromatics, as in our previous work [14-17].

There have been several studies on soot formation in PPFs. The most relevant ones in the present context are those with two ingredients: a) a two-stage combustion, with a premixed flame and a diffusion flame sandwiching a lightly sooting region, in an "interdependent regime" [18] and b) chemical speciation including aromatics and other soot precursors. A broad study on this type of flames using heptane as a Diesel fuel surrogate was conducted in [19-20], but these authors' experimental emphasis was not on soot formation, even though they did consider numerically the effect of strain rate and equivalence ratio on critical soot precursors. A computational follow-up study from the same lab, partially validated with the experimental data in [19-20] on purely diffusive flames, focused on the effect of parent fuel molecular structure on soot formation [21].

\section{Experimental Methods}

Burner geometry and experimental techniques are extensively discussed in previous articles [16-17] and only a brief description will be provided here. Combustion is established in a counter flow burner, including a nitrogen shroud that shields the flame from room drafts and ensures burning in the controlled atmosphere that is determined by the composition of the feed streams. The combustor consists of two identical opposed converging nozzles with an area ratio of nine, and an internal diameter of $6.35 \mathrm{~mm}$ at the outlet. The premixture is issuing from the bottom nozzle, the oxidizer from the top one and each convergent section is preceded by a short straight section containing glass beads and meshes to uniformize the flow coming from the feed lines. Sampling starts by drawing gas through a small silica capillary tube $(\mathrm{OD} / \mathrm{ID}=0.14$ $\mathrm{mm} / 0.10 \mathrm{~mm}$ ), connected to the GC-MS system by a heated metal tube. The probe tip is positioned near the flame axis and a motorized vertical stage displaces the combustor allowing for the scan of the entire flame structure. To collect a sample, a valve separating the GC-MS from the line is opened and the sample is drawn into the sample storage volume that had been initially kept under vacuum $(<1 \mathrm{mbar})$. The line and the valve are kept at $423 \mathrm{~K}$ to prevent condensation of heavy species. Once the sample is retrieved from the flame, it is split into three columns whose outlets are connected to different sensors: a Thermal Conductivity Detector (TCD) for $\mathrm{H}_{2}, \mathrm{O}_{2}$ and $\mathrm{N}_{2}$, a Flame Ionization Detector (FID) for $\mathrm{CO}, \mathrm{CO}_{2}$, and hydrocarbons up to $\mathrm{C}_{2}$, with a methanizer converting $\mathrm{CO}$ and $\mathrm{CO}_{2}$ to $\mathrm{CH}_{4}$, and a Mass Spectrometer (MS) for larger hydrocarbons and aromatics up to acenaphthylene. Gaseous calibration is performed with calibrated bottles $\left(\mathrm{Scotty}^{\circledR}\right.$ ) for $\mathrm{CO}, \mathrm{CO}_{2}, \mathrm{C}_{2} \mathrm{H}_{2}, \mathrm{C}_{2} \mathrm{H}_{6}$, while calibrated flows are obtained with flow controllers for $\mathrm{CH}_{4}, \mathrm{C}_{2} \mathrm{H}_{4}, \mathrm{H}_{2} \mathrm{O}_{2}$ and $\mathrm{N}_{2}$. The MS is calibrated both with reference gas mixtures $\left(\right.$ Scotty ${ }^{\circledR}$ ) and with liquid mixtures of the compound of interest, atomized with an electrospray in a stream of hot nitrogen that allows vaporization and perfect mixing. Knowledge of the mass flow rate of the mixture (through a syringe pump) and of the nitrogen stream leads to the production of a calibrated flow of heavy hydrocarbons. The analysis is run on-the-fly while the probe is kept in idle state until the subsequent sample is drawn. The cumulative error 
in measured concentrations is estimated at $\pm 7.5 \%$ for light species (up to $32 \mathrm{AMU}$ ) and $\pm 15 \%$ for the heavier ones by considering the uncertainties associated with calibration, sampling and analysis procedures. Temperature measurements are performed with a $50 \mu \mathrm{m} \mathrm{Pt} / \mathrm{Pt}-13 \% \mathrm{Rh}$ cylindrical bead thermocouple and by thin filament pyrometry using a $13 \mu \mathrm{m}$ SiC wire. Standard corrections for radiative losses are applied to the thermocouple measurements.

The relative position between the probe measuring point and the blue chemiluminescent layer of the diffusion flame is recorded with a digital camera. This distance is measured with an accuracy of $+/-50 \mu \mathrm{m}$ by image processing and is used to reconstruct the spatial profiles and correct for the probe intrusiveness, in case it did affect the actual position of the flame with respect to the boundaries. As reported in [17], this approach yields spatially resolved measurements even in thin flames under high-pressure conditions.

\subsection{Computational modeling}

The experimental study is supplemented with one dimensional computational modeling of the flames using the OPPDIFF code [22] integrated with the CHEMKIN [23] and the transport [24] subroutine libraries. The detailed chemistry is modeled with two chemical mechanisms: USCMechII [25] that is optimized for the prediction of laminar flame speed of flames fueled by C1C4 hydrocarbons, and the mechanism in [26], heretofore referred to in brief as Pitsch mechanism tracking the aromatic growth up to relatively large species. Multicomponent diffusion coefficients and thermal diffusion are accounted for in the transport model provided with the mechanisms. In registering the experimental profiles with the computational ones the blue chemiluminescence of the diffusion flame is overlapped with the position of the computed peak concentration of $\mathrm{CH}_{2}{ }^{*}$ on the oxidizer side of the Gas Stagnation Plane (GSP).

To account for possible departures in the boundary conditions from plug flow, we model the baseline diffusion flame with a two-dimensional axisymmetric model including the flow in the nozzles and shroud housing, using COMSOL Multiphysics (Comsol Inc.). A simplified chemical reaction mechanisms using 10 species and 5 reactions [27] is used for these simulations. The model yields modified boundary conditions in terms of both value and axial gradient of the axial velocity component along the centerline. Once these modified boundary conditions are used in the one-dimensional Chemkin calculations, the temperature profile along the centerline is found in good agreement with the results from the 2D-simulation. Further details are presented in Appendix A.

\subsection{Selection of experimental condition}

There are many degrees of freedom that we can vary in this variable composition two-stream problem. After some trial-and-error involving preliminary computations, stabilizing flames and checking their sooting behavior, we adopted the following approach:

1) We stabilized a slightly sooting $\mathrm{C}_{2} \mathrm{H}_{4} / \mathrm{O}_{2} / \mathrm{N}_{2}$ baseline diffusion flame by counterflowing fuel and inert with a $\mathrm{O}_{2} / \mathrm{N}_{2}$ stream, corresponding to equivalence ratio $\Phi=\infty$;

2) The momentum fluxes at the boundaries were balanced to position the GSP approximately midway between the two nozzles;

3) Temperature and, consequently, soot loading were controlled by diluting the flames with nitrogen to ensure a moderate soot loading that would be compatible with the chemical characterization of the flame structure and soot precursors; and 
4) We gradually modified the composition of the stream to lower the equivalence ratio to $\Phi=3$, by holding constant the stoichiometric mixture fraction, $Z_{s t}$, the peak temperature and the overall strain rate, $a$.

The overall strain rate is defined as $a=\frac{V_{o x}+V_{f}}{L}$, where $V_{o x}$ and $V_{f}$ are the mass averaged velocities in the oxidizer stream and in the fuel stream at the nozzles, and $L=7.8 \mathrm{~mm}$ is the nozzle separation. It is held fixed at $50 \mathrm{~s}^{-1}$. The stoichiometric mixture fraction is defined as $Z_{s t}=\left(1+s Y_{F F} / Y_{O O}\right)^{-1}$, where $\mathrm{s}$ is the mass-based stoichiometric coefficient, $Y_{O o}$ the mass fraction of oxygen in oxidizer side and $Y_{F F}$ is either the mass fraction of the fuel in the diffusion flame case or of the fuel leftover in the postflame region of the premixed flame, as a result of its rich composition, after assuming complete conversion to $\mathrm{CO}_{2}$ and $\mathrm{H}_{2} \mathrm{O}$ in the premixed flame. $Z_{\text {st }}$ was kept constant to stabilize the diffusion flame at the same distance from the GSP. In essence the procedure amounts to a perturbation of the baseline diffusion flame brought about by the injection of oxygen in the fuel stream, while anchoring conditions on the oxidizer side of the diffusion flame. Table 1 reports the following variables: mole fractions, temperature $\left(\mathrm{T}_{\mathrm{f}}\right.$ and $\mathrm{T}_{\text {ox }}$ ) and mass averaged velocities $\left(V_{o x}\right.$ and $\left.V_{f}\right)$ of the feed streams, peak temperature $\left(\mathrm{T}_{\max }\right)$, stoichiometric mixture fraction $\left(Z_{s t}\right)$, the actual velocity along the centerline at the boundary on the fuel side and the oxidizer side $\left(v_{f}\right.$ and $\left.v_{o x}\right)$ and their axial gradients $\left(\frac{\partial v_{f}}{\partial z}\right.$ and $\left.\frac{\partial v_{o x}}{\partial z}\right)$, respectively. The last two couple of entries were obtained from the $2 \mathrm{D}$ simulations described in Appendix A.

Images of five flames are presented in Fig. 1, showing the diffusion flame at the top and three partially premixed ones below in order of decreasing $\Phi(\Phi=6.5, \Phi=5$, and $\Phi=3)$, each but the first one showing a double (two-stage) flame structure with a premixed flame at the bottom, a diffusion flame at the top and a soot layer in between. The second to the last image is too sooty for the premixed flame component to be visible and for the flame to be probed. Thus, a flame with the same equivalence ratio, henceforth labeled $\Phi=3^{*}$, but lower peak temperature $\left(\mathrm{T}_{\max }=1800 \mathrm{~K}\right.$ ) is shown as the bottom figure. The orange line superimposed on the images highlights the position of the GSP as identified by superimposing the blue chemiluminescent layer of the diffusion flame in the images with the peak concentration of $\mathrm{CH}_{2}{ }^{*}$ in the computational results.

The premixed flame is stabilized on the fuel-side of the stagnation plane, where the axial velocity equals the laminar flame speed of the stretched flame. With decreasing equivalence ratio, the laminar flame speed increases and the premixed flame moves further away from the GSP. The diffusion flame is stabilized on the oxidizer side of the GSP. The three-layer structure is visible in some of the images in Fig. 1 and the soot region appears to separate progressively from the diffusion flame, as the equivalence ratio is lowered. As a result we could observe a different level of coupling of the premixed flame with the diffusion flame.

Obviously partial premixing occurs naturally in turbulent practical system with the oxidizer being invariably air. However, we preferred to synthesize our own oxidizer and control flame conditions as described above, because this approach makes it for a "cleaner" system in the sense of revealing the controlling phenomenology unambiguously. In general we observed that the value of the mixture fraction has a profound influence on the relative position of flame(s) and GSP, the coupling of the two flame components and their sooting behaviour. As a result, one needs to generalize conclusions carefully. 


\section{Results and discussion}

\subsection{Temperature and major species}

The measured and computed temperature profiles of the five flames are shown in Fig. 2. Only computational results are presented for the $\Phi=3$ flame since, as mentioned earlier, it could not be probed in detail because of the excessive soot loading. To make direct comparisons between the flames, the origin of the axial coordinate in the abscissa is chosen to coincide with the GSP, with negative values on the premixed flame side, when present, and positive ones on the diffusion flame side. This shift is applied to all subsequent plots to better contrast the two components of the two-stage flame. The simulations were performed using either plug-flow boundary conditions or the modified velocity boundary conditions from the 2D simulation (see Table 1 and Appendix A). We observe good agreement between measurements and simulations in both cases, although the modified boundary conditions performed measurably better, especially at lower equivalence ratios. We note a mild disagreement on the fuel side of the stagnation plane, with the measured data underestimated by the computational ones for all the flames but the $\Phi=3^{*}$. This "shoulder" in the measured temperature profile was already observed in prior studies on purely diffusive flames of ethylene in counterflow [14]. Its origin is not yet clear, but the data suggest that it persists also in the phi $=5$ and 6.5 flames that are thermally stabilized by the diffusion flame. There are modest differences brought about by the selection of the detailed chemistry. The differences are more significant for the $\Phi=3$ and $3 *$ flames and are attributed to discrepancies in the prediction of the stretched laminar flame speed that affect the width of the computed temperature profile. We also note that plug flow boundary conditions, as opposed to the modified ones, involve a temperature gradient at the fuel nozzle for the $\Phi=3$ flame, contrary to the experimental evidence from temperature measurements in proximity of the fuel nozzle. The modified velocity boundary conditions also lead to significantly improved predictions of the measured temperature width for the $\Phi=3^{*}$ flame. They will be used in the remainder of the comparisons because they take into account the effects of the actual burner geometry on the velocity profile.

Figure 3 presents the mole fraction profiles of $\mathrm{C}_{2} \mathrm{H}_{4}, \mathrm{O}_{2}$ and $\mathrm{CO}_{2}$ for the four probed flames in Fig. 2. As typical of diffusion flames, fuel and oxidizer are null at the location of the diffusion flame. However, for the partially premixed flames we observe that the $\mathrm{C}_{2} \mathrm{H}_{4}$ disappears before the diffusion flame side of the dual flame structure, indicating that the diffusion flame itself is fueled by combustion intermediates formed in the post premixed flame region rather then by unburned $\mathrm{C}_{2} \mathrm{H}_{4}$.

\subsection{Computed temperature-time history and heat release rates}

To provide a glimpse of the structure of these flames Fig. 4 (top) shows the computed temperature profiles with overlapping GSPs for all 5 flames. It is also instructive to compute the volumetric heat release rate as plotted in Fig. 4 (middle) as a function of the axial coordinate. Starting with the diffusion flame as the base line case, we notice that its typical temperature profile is broadened as a result of the injection of oxygen on the fuel side and the lowering of the equivalence ratio by developing a "shoulder" in approximate coincidence with the location of the peak of heat release. The "shoulder" is stretched to occupy the majority of the domain for negative values of the abscissa for the $\Phi=3$ flame. The temperature profile is fixed on the oxidizer side as a result of the selection of constant $Z_{\mathrm{st}}$, strain rate and $\mathrm{T}_{\max }$. The total width of 
the temperature profile decreases when the flame maximum temperature is lowered in the $\Phi=3 *$ case as a consequence of a reduction in the laminar flame speed of the mixture. The leaning out of the flames shifts the heat release progressively from the diffusion flame on the right of the GSP to the premixed one on its left. In particular, spatial integration of these profiles showed that the diffusion flame contributes $100 \% 80 \%, 68 \%$, 26\% and 33\% of the total heat release for $\Phi$ equal to $\infty, 6.5,5$ and 3 and $3^{*}$, respectively. The provisional conclusion is that the premixed flames are obviously thermally coupled to the diffusion flames. In fact, they can not be stabilized in the absence of the latter. As we will show in the ensuing discussion, they are also chemically coupled even with respect to the formation/consumption of critical soot precursors such as the aromatics.

We also note that on the basis of the flame luminosity, of the decay rate of the measured temperature and of microsampling challenges, that the flames under partially premixed conditions are more sooty than the diffusion flame, the lower the value of $\Phi$, the larger the soot load. There may be a preliminary explanation for the observed trends in our experiments. Figure 4 (bottom) presents the temperature-time history with the temporal abscissa obtained by integrating in space the inverse of the computed velocity. The profiles were shifted to ensure coincidence of the beginning of the increase in temperature. As oxygen is added on the fuel side, we notice that the temperature rises much sooner and there is more time for soot kinetics to act at higher temperatures. This increase in temperature coupled with the increased distance of the premixed flame component from the diffusion flame may be responsible for the observed increase in soot formation.

\subsection{Major intermediates}

Figure 5 shows the mole fractions profiles of major intermediates $\mathrm{CO}$ and $\mathrm{H}_{2}$, as well as $\mathrm{CH}_{4}$, for the three flames probed in detail. We dropped both $\Phi=3$ flames from further consideration in view of the significant discrepancy between the two models and the incompleteness of the experimental dataset. In the present figure and many of the following ones, we report the results with the USC model using solid lines and those with Pitsch mechanism using dashed lines. We find that $\mathrm{CO}$ and $\mathrm{H}_{2}$ are the primary fuel "products" in the post flame region of the premixed flame to feed the diffusion flame, consistently with the findings in [20]. We also observe that there is disagreement between measurements and computational results especially with respect to the peak concentrations for $\Phi=5$.

Moving up with the carbon atoms, we consider next acetylene, a critical intermediate both with respect to the aromatic growth via the HACA mechanism, and subsequent soot nucleation and surface growth [8,9]. Figure 6 shows the mole fraction profiles compared with the model predictions and the computed volumetric production rate. We notice that the measured peak concentrations are similar in all cases unlike the model predictions that suggest increasing concentrations at lower equivalence ratios. Our findings are especially surprising in the light of the larger soot loading of leaner flames. They are also in contrast with the computational trends in [20, Fig. 15 ibid] for partially premixed heptane flames in air. We also notice that the profiles broaden on the left side as a result of leaning out the mixture, suggesting an increased contribution of the premixed flame. This behavior is confirmed by the computed production rates that, regardless of the chemical mechanism, show an increasing contribution from the postflame region of the premixed flame at negative values of the abscissa, that is, on the left of the GSP. 
Critical stable intermediates in the process leading to the first aromatic ring and to the aromatic growth include $\mathrm{C}_{3} \mathrm{H}_{4}$ isomers, i.e. allene and propyne. As discussed in Appendix $\mathrm{B}$, those isomers intervene in the propargyl $\left(\mathrm{C}_{3} \mathrm{H}_{3}\right)$ route to benzene formation and aromatic growth [7,9]. Their lumped concentration profile is shown in Fig. 7 exhibiting an increase in concentration with lowering equivalence ratio and a progressively increasing role of the premixed side of the dual flame. Both chemical mechanisms are in reasonable agreement with the experimental results, whereas additional C3 comparisons also shown in the same figure show a deteriorating agreement for propene and, to a lesser extent, for propane, especially at the lowest equivalence ratio. Turning to $\mathrm{C} 4 \mathrm{~s}$ shown in Fig. 8, we report profiles for the lumped isomers of ring-stabilized butadiene and dimethylacetylene as $\mathrm{C}_{4} \mathrm{H}_{6}$, vinylacetylene as $\mathrm{C}_{4} \mathrm{H}_{4}$, and diacetylene as $\mathrm{C}_{4} \mathrm{H}_{2}$. $\mathrm{C} 4 \mathrm{~s}$ also significantly contribute to the formation of the first aromatic ring, reacting with acetylene and vinyl radicals (see appendix B). They also contribute to the aromatic growth [9]. Experimentally, we notice that as the equivalence ratio is lowered, $\mathrm{C}_{4} \mathrm{H}_{2}$ follow opposite trends compared to $\mathrm{C}_{4} \mathrm{H}_{6}$ and $\mathrm{C}_{4} \mathrm{H}_{4}$, the first decreasing and the other two increasing. In general neither model seems to perform well either in absolute terms or in capturing the observed trends. Before turning to the aromatics, we report in Fig. 9 profiles for cyclopentadiene and methycyclopentadiene, both resonance stabilized with an expected role in the cyclization process and in the aromatic growth of polycyclics. As the equivalence ratio is lowered, both of them increase, with the profile shifting gradually towards the premixed side, a trend that is properly captured by the models at least for cyclopentadiene, the only species included in the mechanisms.

Aromatics deserve a separate treatment with a focus first on benzene since, when starting from small parent molecules, the formation of the first ring is often suggested to be the chemical kinetic bottleneck [9]. Figure 10 shows benzene profiles for the three cases showing an increase in concentration with the lowering of the equivalence ratio and an increased participation of the premixed branch of the flame in its production rate, as shown in Fig. 10b. The data are in reasonable agreement with USC-Mech, whereas Pitsch's mechanism tends to overpredict all concentrations but that in the purely diffusive flame. Also in this case our findings contrast with the computational trends in [20] (Fig. 15 ibid) for partially premixed heptane flames in air. A path analysis to benzene using the USC mechanism, that is the only one reasonably predicting its concentrations, is briefly presented in Appendix B to rationalize the experimental findings. Under partial premixing it predicts an increasingly larger contribution of the C3 path to benzene formation when lowering the equivalence ratio. However, the model is not capable to reproduce some intermediate steps leading to the formation of the first aromatic ring, even if the benzene concentrations are in relatively good agreement with the experimental results.

The last comparison is presented in Fig. 11 for the larger aromatics up to pericondensed ones such as acenaphthylene. They are not included in the USC Mech but are partially considered in in Pitsch's mechanism. With lowering equivalence ratio, indene and some alkylated aromatics such as toluene, ethylbenzene, xylene and methyl- naphthalene (the latter two not shown here) increase, whereas fully condensed aromatics like naphthalene and acenaphthylene either do not seem to vary appreciably or decrease. These results suggest that alkylated aromatics could have increasingly higher importance in the growth leading to soot formation, when lowering the equivalence ratio. Pitsch's mechanism captures well the observed trends for ethylbenzene and 
indene, overestimates the concentration for phenylacetylene, naphthalene and acenaphthylene, whereas it underestimates toluene.

\subsection{Comparison with strained purely premixed flames}

Let us recapitulate our findings. As $\Phi$ is lowered at fixed $T_{\max }$ and $Z_{s t}$ :

a) the soot load increases, as summarily shown by the pictures in Fig. 1;

b) the temperature increases in the postflame region of the premixed branch of the dual flame (Fig. 4), with the discussed "shoulder" appearing more and more prominent;

c) the premixed component contributes more and more to the formation of soot (precursors), as evidenced by the production rates of $\mathrm{C}_{2} \mathrm{H}_{2}$ and $\mathrm{C}_{6} \mathrm{H}_{6}$ in Figs. 6 an 10, respectively; and

d) fuel concentration decreases, as shown in Table 1.

This behavior is contrary to the computational results in [20, see Figs 13, 15 and 19 ibid]. An explanation rests on the nature of the partial premixing in [20] that is achieved using only air as the oxidizer, as opposed to the present situation in which the "air" is synthesized with different concentrations of oxygen and nitrogen, to satisfy the constraint of constant $Z_{\text {st }}$. Because of the approach in [20], $Z_{s t}$ of the diffusion flame increases when the equivalence ratio is lowered, the maximum temperature location moves progressively closer to the GSP, with enhanced oxidation provided by the diffusion flame. In our case, the position of the diffusion flame component of the two-stage system is fixed with respect to the GSP, as shown in Fig. 2 . When we lower the equivalence ratio, the premixed component of the flame moves upstream, away from the GSP because of the increase in laminar flame speed, which progressively shields it from the oxidative attack of radicals diffusing from the diffusion flame component of the flame. On the contrary, at fixed equivalence ratio the premixed flame moves closer to the stagnation plane when the flame maximum temperature is lowered. Clearly, one needs to generalize conclusions carefully since, as already discussed, the value of the mixture fraction has a profound influence on the relative position of flame(s) and GSP, the coupling of the two flame components and their sooting behavior.

Now, at least computationally we wish to compare the premixed portion of the two-stage combustion system under consideration with an ordinary strained premixed flame. To that end, we compare our results to those obtained by stabilizing a strained premixed flame against a hot nitrogen stream at a temperature matching the same peak value of the present experiments, that is $2000 \mathrm{~K}$. The hot nitrogen velocity at the boundary is tuned to have the premixed flame stabilized in the same relative position with respect to the stagnation plane, as in the partially premixed flame configuration. Figure 12 shows the computed results for the two sets of flames, the $\Phi=5$ and $\Phi=6.5$ PPFs and their strained purely premixed counterparts. We plot the temperature in the top panel, $\mathrm{H}$ and $\mathrm{OH}$ that have a major role in the soot context both from a formation and oxidation perspective in the second and third panel and the computed profiles of $\mathrm{C}_{6} \mathrm{H}_{6}$, that is chosen here as a "surrogate" for soot in the panel below. We observe that the structure of the two sets of flames have the following notable difference: the radical concentrations benefit from a significant feedback from the diffusion flame component with radicals diffusing to the premixed side. The net effect is both a narrowing of the benzene concentration profile and a lowering of the peak concentration, as compared to the purely premixed strained flame in which the radical concentrations level off and eventually decay in the post flame region. This behavior is even more significant since the temperature-time histories in the two sets of flames, shown in the bottom panel, are not exactly matched and the 
PPFs tend to have histories more favorable to soot formation, with a slightly longer residence time at high temperature.

We shall now consider the effect of a temperature change. We will explore the $\Phi=5$ case computationally, since the model has already been validated in the partially premixed context with the present experiments. Figure 13 shows the same type of comparison of computed profiles as in Fig. 12 for conditions in which the peak temperature is changed from $2000 \mathrm{~K}$ to $1800 \mathrm{~K}$. The same considerations we made in the discussion of Fig. 12 apply also here. The temperature dependence is the same for both flames, with a lowering of the benzene concentration as the temperature is lowered. The "asymptotitc" value achieved in the temperature time history on the premixed flame side of the PPF drops from $1720 \mathrm{~K}$ to $1580 \mathrm{~K}$, with a reduction that is significantly more pronounced in such flames as compared to the purely premixed ones because of the enhanced coupling with the diffusion flame component when lowering the laminar flame speed of the fuel mixture. The computed temperature dependence is reflected in the change in flame soot load qualitatively depicted in the bottom two images in Fig. 1, when at fixed $\Phi=3$, we lowered the peak temperature to $1800 \mathrm{~K}$. In fact, we managed to probe in detail such a flame, although for economy of space we chose not to present the detailed data in this article.

In conclusion, if we rely on benzene as a soot surrogate, the computational comparison between PPFs and their purely premixed strained counterparts shows that the two sets of flames behave likewise in terms of dependency of sooting tendency on equivalence ratio and peak temperature. Furthermore, PPFs, probably as a result of the back diffusion of key radicals such as $\mathrm{H}$ and $\mathrm{OH}$ from the diffusion flame component, have a lower tendency to soot as compared to purely premixed ones.

\section{Conclusions}

We studied an incipiently sooting ethylene diffusion flame that developed a double (premixed/diffusion) flame structure when oxygen was added on the fuel side at constant peak temperature and stoichiometric mixture fraction. Microprobe gas sampling followed by GC-MS analysis and temperature measurements, as well as a comparison with ancillary computational results using two chemical kinetic mechanisms, lead to the following principal conclusions:

1) At equivalence ratio $\Phi=6.5$ and $\Phi=5.0$, the dual flame sandwiches an incipiently sooting layer and, as the equivalence ratio decreases, soot formation increases, a trend that is qualitatively observed also at $\Phi=3$;

2) The premixed component of the flames and the diffusion flame one are not only thermally coupled, but also chemically coupled with the premixed flame fueling the diffusion flame with $\mathrm{CO}, \mathrm{H}_{2}$ and larger combustion intermediates;

3) As the equivalence ratio decreases at constant maximum temperature and stoichiometric mixture fraction, the post flame region on the premixed side contributes more and more to the production of critical soot precursors (e.g., $\mathrm{C}_{2} \mathrm{H}_{2}$ and $\mathrm{C}_{6} \mathrm{H}_{6}$ ) and alkylated aromatics appear to gain importance in the path leading to soot formation;

4) Simulations showed that as the peak temperature decreases the peak concentration of benzene decreases, suggesting lower sooting trend that is qualitatively confirmed experimentally; 
In closure, this two-stage combustion system presents a particularly challenging testbed for modelers with features of both premixed flames, diffusion flames and variable coupling between the two, depending on the value of $\Phi$ and of the flame maximum temperature. We developed a database with the measurements of primary reactants, products and intermediates, including critical soot precursors up to 3-ring aromatics that is available to modelers for further refinements of chemical kinetic mechanisms.

\section{Acknowledgements}

The authors gratefully acknowledge the financial support of the U.S. Army Research Office (Grant\# W911NF-14-1-0264, Dr. Ralph A. Anthenien, Program Director), Professor T. Lu (UConn) for providing the reduced mechanism used in the 2D simulations and Mr. Nick Bernardo for help in the construction of the hardware.

\section{References}

1 N. Peters, Turbulent Combustion, Cambridge University Press, U.K., 2000.

2 A.R. Masri, Proc. Combust. Inst. 35 (2015) 1115-1136.

3 G. Amantini, J.H. Frank, B.A.V. Benneth, M.D. Smooke, A. Gomez, Combust. Flame 150 (2007) 293-319.

4 J.E. Dec, SAE Technical paper 970873 (1997).

5 J.E. Dec, Proc. Combust. Inst. 32 (2009) 2727-2742.

6 H.S. Hura, I. Glassman, Proc. Comb. Inst. 22 (1988) 371-378.

7 J.A. Miller, C.F. Melius, Combust. Flame 91 (1992) 21-39.

8 H. Wang, M. Frenklach, Combust. Flame 110 (1997) 173-221.

9 H. Richter, J.B. Howard, Prog. Energy Combust. Sci. 26 (2000) 565-608.

10 H. Bockhorn, A. D’Anna, A.F. Sarofim, H. Wang (Eds.), Combustion generated fine carbonaceous particles, KIT Scientific Publishing, Karlsruhe, DE, 2009.

11 A. D’Anna, Proc. Combust. Instit. 32 (2009) 593-613. 
12 H. Wang, Proc. Combust. Inst. 33 (2011) 41-67.

13 S.C. Li, F.A. Williams, Proc. Combust. Inst. 28 (2000) 1031-1038.

14 F. Carbone, A. Gomez, Combust. Flame 159 (2012) 3040-3055.

15 F. Carbone, A. Gomez, Combust. Flame 161 (2014) 453-464.

16 L. Figura, A. Gomez, Combust. Flame 161 (2014) 1587-1603.

17 L. Figura, F. Carbone, A. Gomez, Proc. Combust. Inst. 35 (2015) 1871-1878.

18 H.P. Mungekar, A. Atreya, J. Heat. Transf. 128 (2006), 361-367.

19 P. Berta, I.K. Puri, S.K. Aggarwal, Proc. Combust. Inst. 30 (2005) 447-453.

20 P. Berta, S.K. Aggarwal, I. Puri, Combust. Flame 145 (2006) 740-764.

21 X. Fu, X. Han, K. Brezinsky, S. Aggarwal, Energy Fuels 27 (2013), 6262-6272.

22 A.E. Lutz, R.J. Kee, J.F. Grcar, F.M. Rupley, , Report MS-9042, SAND96-8243 (1996) , Sandia National Laboratories.

23 R.J. Kee, F.M. Rupley, J.A. Miller, Sandia Report SAND89-8009 (1989), Sandia National Laboratories.

24 R.J. Kee, J. Warnatz, J.A. Miller, Sandia Report SAND83-8209 (1983), Sandia National Laboratories.

25 H.Wang, X. You, A.V. Joshi, S.G. Davis, A. Laskin, F. Egolfopoulos, C.K. Law (2007) at http://ignis.usc.edu/USC_Mech_II.htm .

26 K. Narayanaswamy, G. Blanquart and H. Pitsch, Combust. Flame, 157 (2010) 1879-1898.

27 T. Lu, personal communication. 


\section{Appendix A- Two dimensional axisymmetric modelling of the diffusion flame}

Ancillary modelling of the $\Phi=\infty$ flame was performed using COMSOL multiphysics (Comsol Inc.) finite element solver package. The model couples four 2-D axisymmetric solvers of the package, including the low Mach number laminar flow, the heat transfer in fluid, the transport of concentrated species and the reaction engineering modules. The transport model relies on a mixture-averaged determination of the transport coefficients and neglects thermal diffusion effects. With respect to the chemistry, we used the simplified 5-step reaction mechanism shown in Table A1 [27].

The model considers an axis-symmetric cylindrical domain $12.2 \mathrm{~mm}$ in height and $18 \mathrm{~mm}$ in radius) between the nozzle outlets and the internal geometry of the used burner, including the convergent sections of the fuel, oxidizer and shroud nozzles downstream of the straight honeycomb used to laminarize and homogenize the flow. The total area of the computational domain is $920 \mathrm{~mm}^{2}$. Free triangulation is used to generate most of the computational elements even if elongated rectangular elements are used to resolve the flow boundary layers in proximity of the nozzle walls. The total final number of used elements is slightly over 20000 after manual refinements of the triangulation in areas of the solution with sharp gradients.

Boundary conditions are assigned on the axis of symmetry, at the nozzle inlets, at the nozzle wall and on the surface of the cylinder surrounding the outlet of the nozzles. Zero radial gradient conditions are used for all the variables on the axis. Temperature, composition and uniform axial velocity are assigned at the nozzle inlets, based on thermocouple measurements and the total mass flowrate supplied to each nozzle, respectively. Adiabatic, zero diffusive flux and no-slip boundary conditions are assigned at the nozzle walls. Atmospheric pressure and outflow (zero diffusive fluxes) are specified on the external surface of the cylinder.

Figure A1 shows the computed fields of the temperature and of the axial velocity component. As anticipated, in the vicinity of the axis of symmetry there is no radial dependence of the variable, attesting to the local one-dimensionality of the flow. The values of the axial velocity component and its axial gradient on the centerline at the outlet of the nozzles (i.e. $v_{f}$ and $\frac{\partial v_{f}}{\partial z}$, and $v_{o x}$ and $\frac{\partial v_{o x}}{\partial z}$, respectively) were determined and used as input of the one-dimensional code (OPPDIFF [22]). The axial velocity profiles and the temperature profiles are shown in Fig. A2, in a comparison between 1-D model including either reduced or detailed chemistry, and 2-Dreduced chemistry simulations using the same values of the axial velocity and its gradient at the boundaries. The results are very close with a small disagreement in the maximum temperature region and a slightly higher maximum temperature predicted by the simplified chemistry.

The 2-D modelling of the PPFs could not be performed because the simplified kinetic mechanism is not able to predict the laminar flame speed of the used mixtures. When the addition of oxygen is causing only a small perturbation of the temperature field, it is reasonable to assume that the actual velocities and gradients at the nozzle outlet change only slightly as compared to the one achieved when stabilizing the purely diffusive flame. This is confirmed by the good agreement with experiments, especially at the higher values of the equivalence ratio. 


\section{Appendix B- Reaction path analysis to benzene}

A reaction pathway analysis may help evaluate some key differences in the aromatic formation and growth in the investigated PPFs with respect to the baseline purely diffusive flame. Since the formation of the first aromatic ring is the bottleneck to soot formation in ethylene fuelled flames [9], we decided to focus our attention on benzene whose concentration profile is predicted reasonably well by the USC mechanism in all the investigated flames. We performed our analysis backward considering first the reactions leading to benzene formation and the preceding few steps that are partially validated and involve intermediates to benzene formation. We consider first the production (positive) terms in the species equations at each location in the axial profile and integrate it over the entire profile. Subsequently we considered the major species involved in those reactions to continue in the analysis. A post-processing lumping of several isomers of straight chain hydrocarbons is also performed. The results are summarized in Fig B1 where the species in bold are measured and quantified in the experiments.

As expected and generally accepted [9], benzene forms through two main paths: the C3 route, involving propalgyl radical recombination, and the $\mathrm{C} 4$ one, trough the reaction of $\mathrm{C}_{4} \mathrm{H}_{5}$ radical with acetylene. In the purely diffusive flame the C3 path contributes to $60 \%$ of benzene formation, whereas the C4 alternative accounts for the remaining $40 \%$. These percentages are reliable because all the major intermediates involved in propalgyl formation, namely $\mathrm{C}_{3} \mathrm{H}_{4}$, acetylene, cyclopentadiene and methyl and $\mathrm{H}$ radicals (measured through $\mathrm{C} 0-\mathrm{C} 2$ species), and $\mathrm{C}_{4} \mathrm{H}_{5}$ radical (measured through the detection of butadiene) are reasonably well predicted by the model. As the baseline diffusion flame is perturbed with the addition of oxygen and transformed into a PPF, the predicted contribution of propalgyl radical recombination to benzene formation jumps up to $82 \%$ and $85 \%$ for the $\Phi=6.5$ and the $\Phi=5$ flames, respectively. The increase in relative contribution of the $\mathrm{C} 3$ path is qualitatively confirmed by the experimental data because the concentration profile of $\mathrm{C}_{3} \mathrm{H}_{4}$ isomers is predicted with reasonable accuracy in both flames. Nonetheless, the concentration profiles of other key species, i.e. acetylene, butadiene and, to a lesser extent, methane and hydrogen are not properly reproduced by the model so that the actual partitioning between the two paths may differ from the calculated one. 
Figure 1: Images of flames. Top to bottom: $\Phi=\infty$ (purely diffusive flame), $\Phi=6.5, \Phi=5$, and $\Phi=3$, all at $T_{\max }=2000 \mathrm{~K}$. The bottom picture is also for $\Phi=3$ but at lower peak temperature $\left(\mathrm{T}_{\max }=1800 \mathrm{~K}\right)$. The partially premixed ones show a double (two-stage) flame structure, with a premixed flame at the bottom, a diffusion flame at the top and a soot layer in between. The orange line superimposed on the images highlights the position of the GSP.

Figure 2: Measured (symbols) and computed (USC-II mechanism as solid line and Pitsch mechanism as dashed line) temperature versus axial coordinate measured from the GSP. Measurements were performed using either thermocouples (TC) or thin filament pyrometry (TFP). Simulations used either plug-flow boundary conditions (solid lines) or modified velocity boundary conditions from 2D simulations (dashed lines). Fuel is issued from the left (negative abscissa).

Figure 3: Measured (symbols) and computed (USC-II mechanism as solid line and Pitsch mechanism as dashed line) mole fractions of major species versus axial coordinate measured from the GSP. Decreasing equivalence ratio, $\Phi$, top to bottom: $\Phi=\infty, \Phi=6.5, \Phi=5$ and $\Phi=3^{*}$. Simulations used either plug-flow boundary conditions (solid lines) or modified velocity boundary conditions from 2D simulations (dashed lines). Fuel is issued from the left (negative abscissa).

Figure 4: Computed temperature (top) and heat release rate per unit volume (middle) with modified boundary conditions using Pitsch mechanism versus axial coordinate measured from the GSP, for $\Phi=\infty, \Phi=6.5, \Phi=5, \Phi=3$ and $\Phi=3 *$. Bottom: temperature-time history on the premixed side of the domain.

Figure 5: Measured (symbols) and computed (lines) mole fractions of major intermediates, CO, $\mathrm{H}_{2}$ and $\mathrm{CH}_{4}$, versus axial coordinate measured from the GSP. Simulations with USC-II mechanism in solid line and with Pitsch mechanism in dashed line.

Figure 6: Top: measured (symbols) and computed (lines) mole fractions of $\mathrm{C}_{2} \mathrm{H}_{2}$, versus axial coordinate measured from the GSP. Simulations with USC-II mechanism in solid line and with Pitsch mechanism in dashed line. Bottom: computed volumetric rate of production of $\mathrm{C}_{2} \mathrm{H}_{2}$ versus distance from the GSP with both mechanisms.

Figure 7: Measured (symbols) and computed (lines) mole fractions of C3s, versus axial coordinate measured from the GSP. Simulations with USC-II mechanism in solid line and with Pitsch mechanism in dashed line.

Figure 8: Measured (symbols) and computed (lines) mole fractions of C4s, versus axial coordinate measured from the GSP. Simulations with USC-II mechanism in solid line and with Pitsch mechanism in dashed line.

Figure 9: Measured (symbols) and computed (lines) mole fractions of cyclopentadiene and methylcyclopentadiene, versus axial coordinate measured from the GSP. Simulations with USC-II mechanism in solid line and with Pitsch mechanism in dashed line.

Figure 10: Top: measured (symbols) and computed (lines) mole fractions of $\mathrm{C}_{6} \mathrm{H}_{6}$, versus axial coordinate measured from the GSP. Simulations with USC-II mechanism in solid line and with Pitsch mechanism in dashed line. Bottom: computed volumetric rate of production of $\mathrm{C}_{6} \mathrm{H}_{6}$ versus distance from the GSP with both mechanisms. 
Figure 11:Measured (symbols) and computed (lines) mole fractions of larger (>C6) aromatics versus axial coordinate measured from the GSP. Simulations with Pitsch mechanism only.

Figure 12: Partially premixed flames compared to the equivalent strained laminar flame stabilized against a hot nitrogen stream. Top to bottom: profiles of temperature, mole fractions of $\mathrm{OH}, \mathrm{H}$ and $\mathrm{C}_{6} \mathrm{H}_{6}$, and temperature-time history. Simulations use the USC- II mechanism.

Figure 13: Partially premixed flame (solid line) at $\Phi=5$ compared to the equivalent strained laminar flame (dashed line) stabilized against a hot nitrogen stream at $\mathrm{T}_{\max }=2000 \mathrm{~K}$ (blue lines) and $\mathrm{T}_{\max }=1800 \mathrm{~K}$ (purple lines). Top to bottom: profiles of temperature, mole fractions of $\mathrm{OH}$, $\mathrm{H}$ and $\mathrm{C}_{6} \mathrm{H}_{6}$, and temperature-time history. Simulations use the USC- II mechanism.

Figure A1: Temperature field (left) and axial velocity field (right) as obtained by 2-D axissymmetric simulation for the $\Phi=\infty$ flame. The solution includes the domain between nozzles, the domain inside the burner and the annular region surrounding the burner nozzle outlet. Only half of the domain is shown because of axial symmetry.

Figure A2: Comparison of temperature profiles (top) and axial velocity profiles (bottom) of the diffusion flame $(\Phi=\infty)$ along the burner axis. Solutions are calculated using the 2-D model with reduced kinetics (blue line) and the one-dimensional OPPDIFF solver using the modified boundary conditions provided by the 2-D model.

Figure B1: Reaction path analysis of benzene formation with the USC II mechanism in the three investigated flames. Each arrow is labeled with percentage of the production at each step in the pyrolysis process. Species in bold red were detected and quantified by GC-MS analyses. 
Table 1. Flame boundary conditions

\begin{tabular}{llllll}
\hline & $\Phi=\infty$ & $\Phi=6.5$ & $\Phi=5$ & $\Phi=3$ & $\Phi=3 *$ \\
\hline Premixed Flame side & & & & & \\
$\mathrm{C}_{2} \mathrm{H}_{4}$ & 0.330 & 0.310 & 0.300 & 0.275 & 0.220 \\
$\mathrm{O}_{2}$ & 0.000 & 0.140 & 0.180 & 0.275 & 0.220 \\
$\mathrm{~N}_{2}$ & 0.670 & 0.550 & 0.520 & 0.450 & 0.560 \\
$V_{f}[\mathrm{~cm} / \mathrm{s}]$ & 19.8 & 19.8 & 19.8 & 19.8 & 19.8 \\
$\mathrm{~T}_{\mathrm{f}}[\mathrm{K}]$ & 298 & 298 & 298 & 298 & 298 \\
$v_{f}[\mathrm{~cm} / \mathrm{s}]$ & 27.8 & 27.8 & 27.8 & 27.8 & 27.8 \\
$\partial v_{f}[1 / \mathrm{s}]$ & 52.9 & 52.9 & 52.9 & 52.9 & 52.9 \\
\hline$\partial z$ & & & & & \\
$\quad$ Oxidizer side & & & & & \\
$\mathrm{O}_{2}$ & 0.229 & 0.177 & 0.161 & 0.121 & 0.098 \\
$\mathrm{~N}_{2}$ & 0.771 & 0.823 & 0.839 & 0.879 & 0.902 \\
$V_{o x}[\mathrm{~cm} / \mathrm{s}]$ & 21.2 & 21.2 & 21.2 & 21.2 & 21.2 \\
$\mathrm{~T}_{\text {ox }}[\mathrm{K}]$ & 323 & 323 & 323 & 323 & 323 \\
$v_{\text {ox }}[\mathrm{cm} / \mathrm{s}]$ & 34.1 & 34.1 & 34.1 & 34.1 & 34.1 \\
$\frac{\partial v_{o x}}{\partial z}[1 / \mathrm{s}]$ & 32.4 & 32.4 & 32.4 & 32.4 & 32.4 \\
$\mathrm{~T}_{\max }[\mathrm{K}]$ & 2000 & 2000 & 2000 & 2000 & 1800 \\
$Z_{s t}$ & 0.183 & 0.183 & 0.183 & 0.183 & 0.183 \\
\hline
\end{tabular}

TableA1. Reaction Mechanism (courtesy of Prof. Tianfeng Lu)

\begin{tabular}{c}
$\mathrm{C}_{2} \mathrm{H}_{4}+2 \mathrm{O}_{2}=2 \mathrm{CO}+2 \mathrm{H}_{2} \mathrm{O}$ \\
$\mathrm{C}_{2} \mathrm{H}_{4}+3 \mathrm{O}_{2}=2 \mathrm{CO}_{2}+2 \mathrm{H}_{2} \mathrm{O}$ \\
$\mathrm{H}_{2}+2 \mathrm{OH}=2 \mathrm{H}_{2} \mathrm{O}$ \\
$\mathrm{CO}+\mathrm{OH}=\mathrm{CO}_{2}+\mathrm{H}$ \\
$\mathrm{H}+\mathrm{O}_{2}=\mathrm{O}+\mathrm{OH}$ \\
\hline
\end{tabular}



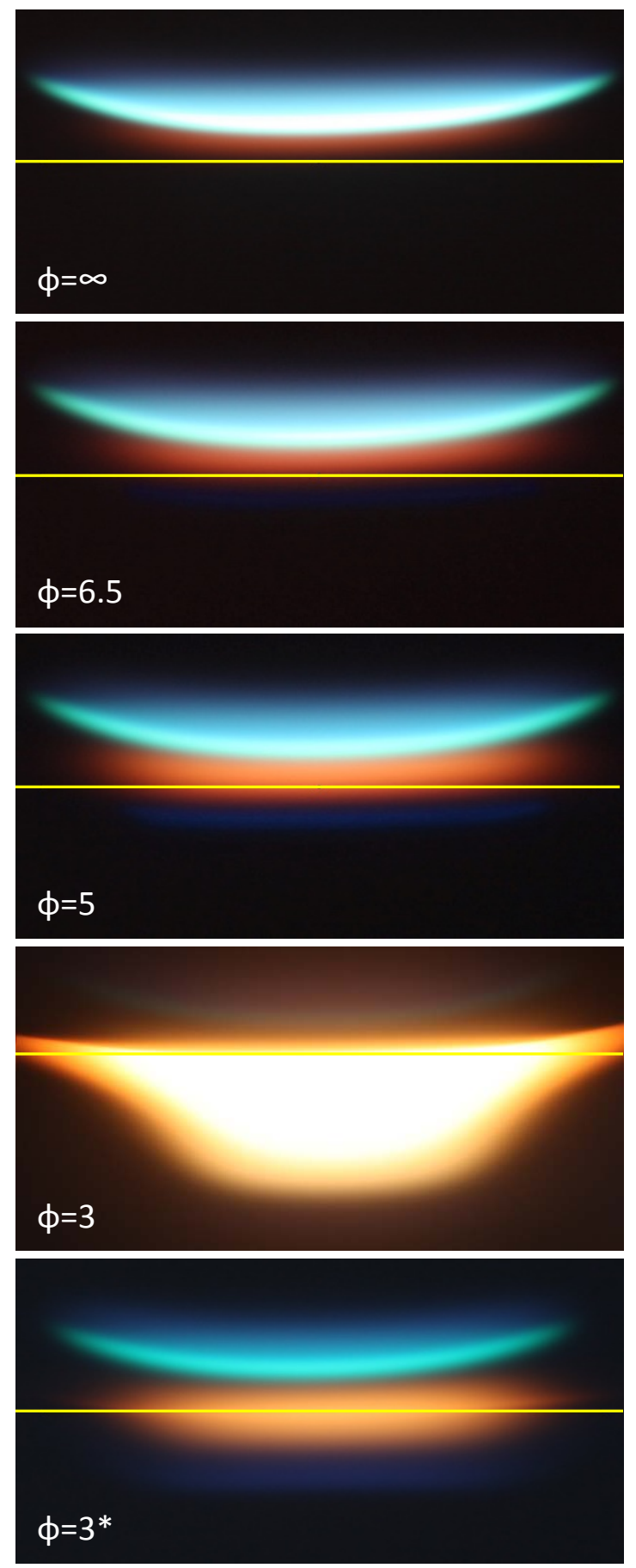

Figure 1: Images of flames. Top to bottom: $\Phi=\infty$ (purely diffusive flame), $\Phi=6.5, \Phi=5$, and $\Phi=3$, all at $\mathrm{T}_{\max }=2000 \mathrm{~K}$. The bottom picture is also for $\Phi=3^{*}$ but at lower peak temperature $\left(\mathrm{T}_{\max }=1800 \mathrm{~K}\right)$. The partially premixed ones show a double (two-stage) flame structure, with a premixed flame at the bottom, a diffusion flame at the top and a soot layer in between. The orange line superimposed on the images highlights the position of the GSP. 

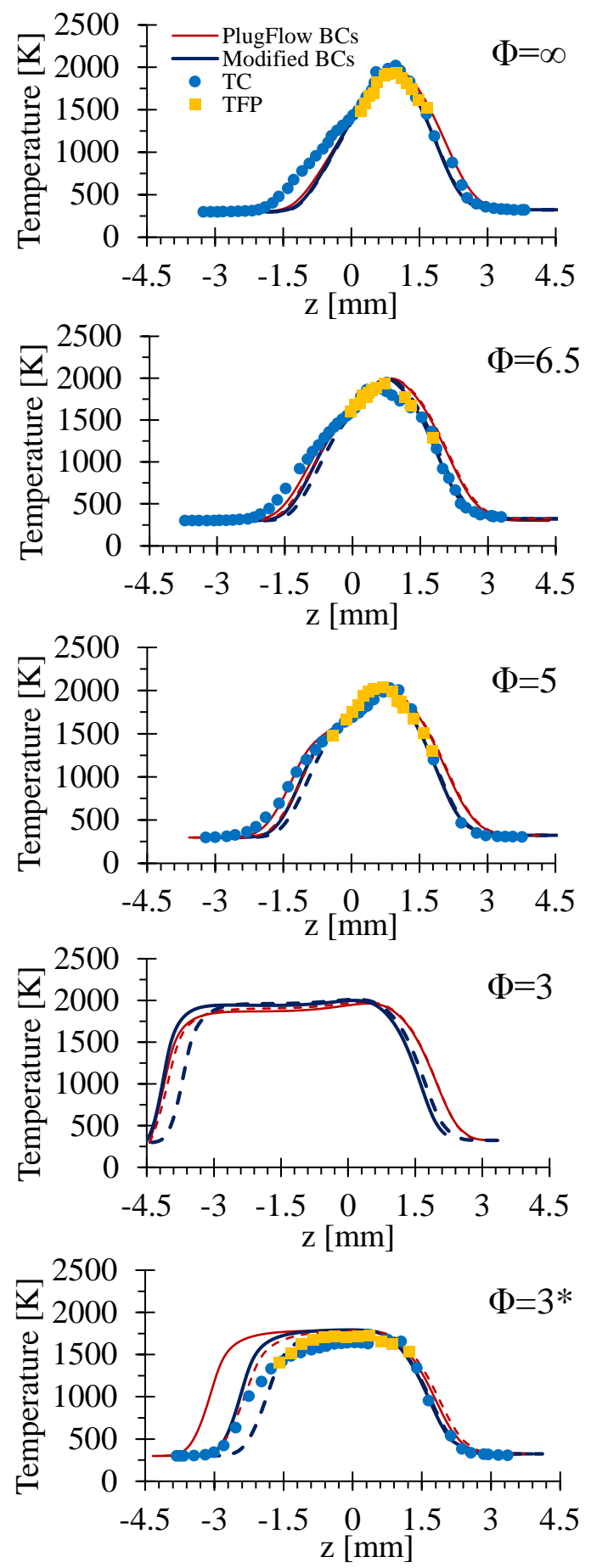

Figure 2: Measured (symbols) and computed (USC-II mechanism as solid line and Pitsch mechanism as dashed line) temperature versus axial coordinate measured from the GSP. Measurements were performed using either thermocouples (TC) or thin filament pyrometry (TFP). Simulations used either plug-flow boundary conditions (thin red lines) or modified velocity boundary conditions from 2D simulations (thick blue lines). Fuel is issued from the left (negative abscissa). 

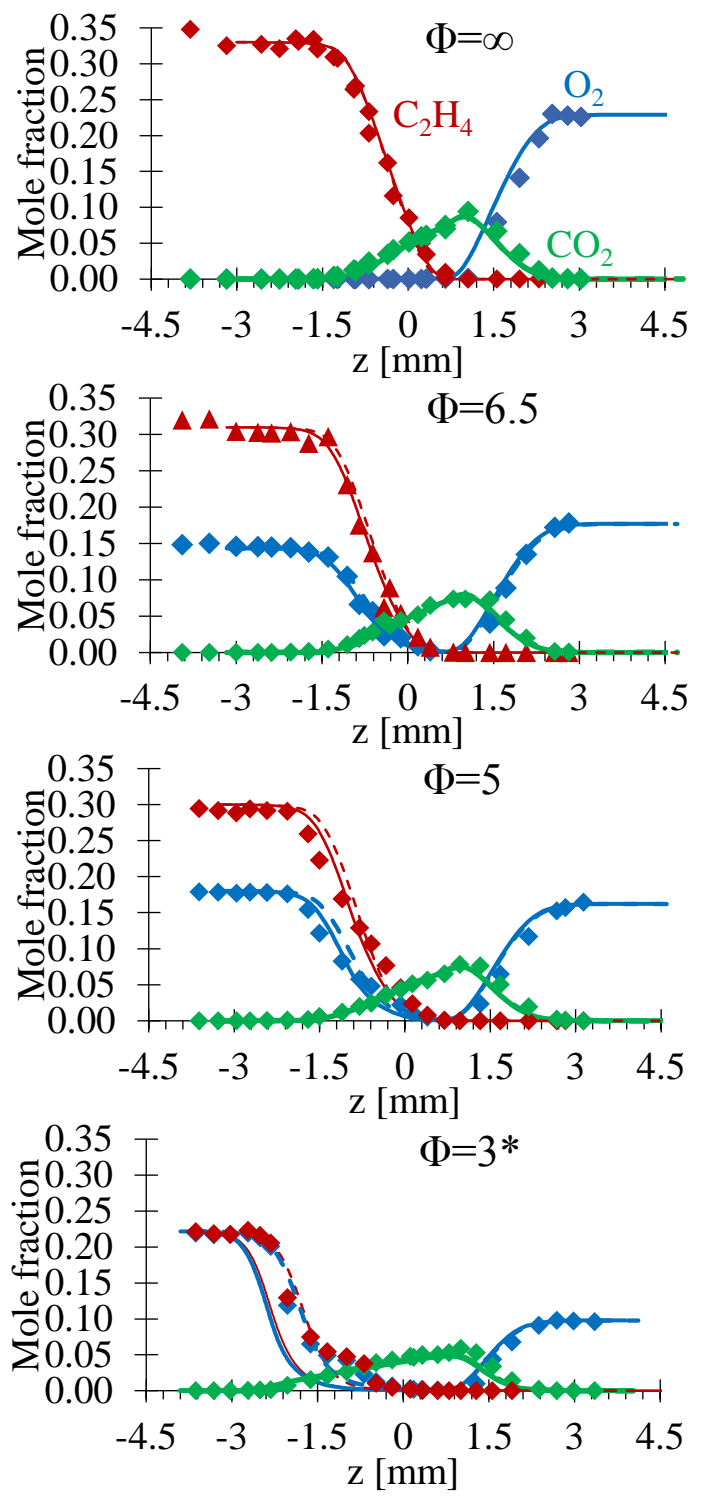

Figure 3: Measured (symbols) and computed (USC-II mechanism as solid line and Pitsch mechanism as dashed line) mole fractions of major species versus axial coordinate measured from the GSP. Decreasing equivalence ratio, $\Phi$, top to bottom: $\Phi=\infty, \Phi=6.5, \Phi=5$ and $\Phi=3^{*}$. Simulations used either plug-flow boundary conditions (thin red lines) or modified velocity boundary conditions from 2D simulations (thick blue lines). Fuel is issued from the left (negative abscissa). 

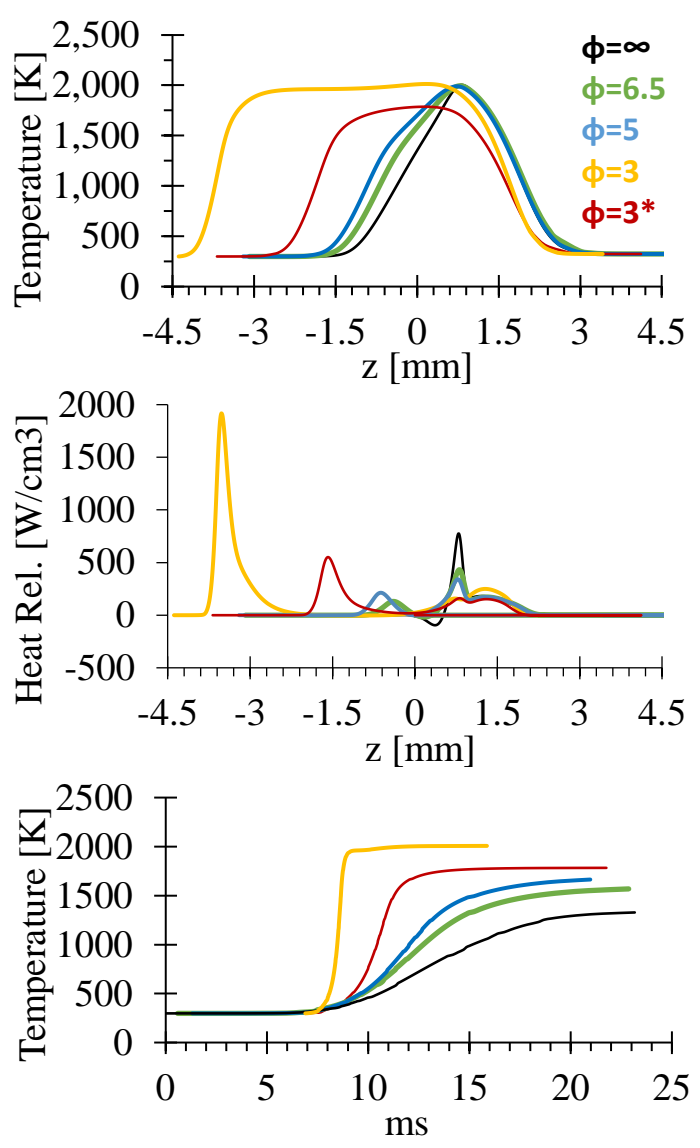

Figure 4: Computed temperature (top) and heat release rate per unit volume (middle) with modified boundary conditions using Pitsch mechanism versus axial coordinate measured from the GSP, for $\Phi=\infty, \Phi=6.5, \Phi=5, \Phi=3$ and $\Phi=3^{*}$. Bottom: temperature-time history on the premixed side of the domain. 

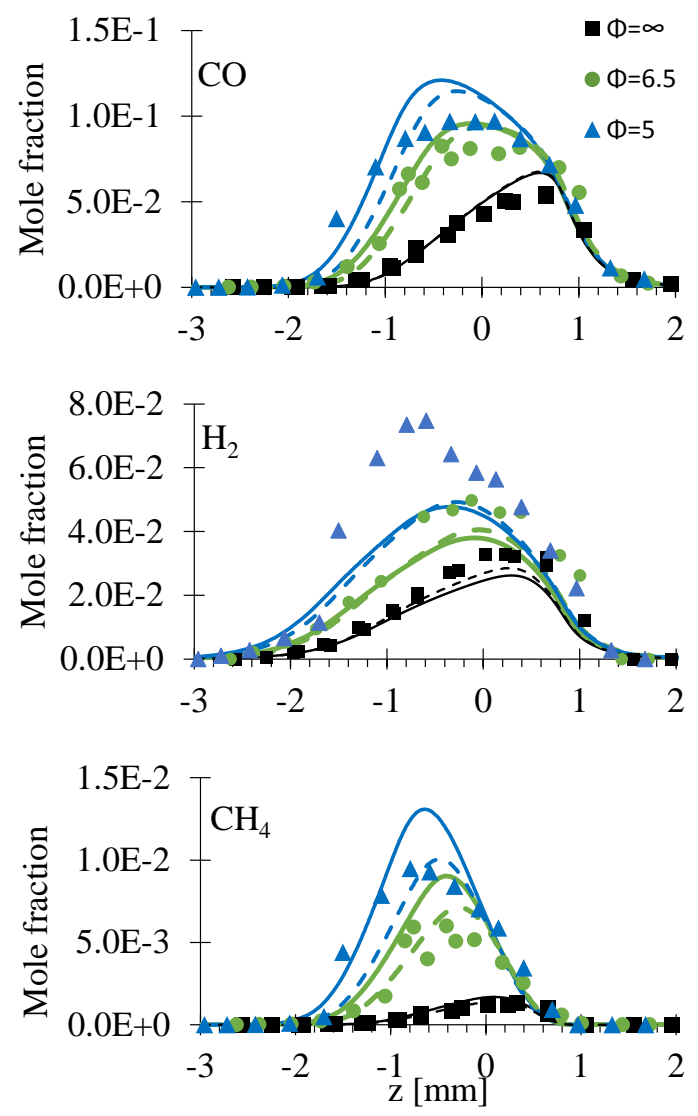

Figure 5: Measured (symbols) and computed (lines) mole fractions of major intermediates, CO, $\mathrm{H}_{2}$ and $\mathrm{CH}_{4}$, versus axial coordinate measured from the GSP. Simulations with USC-II mechanism in solid line and with Pitsch mechanism in dashed line. 

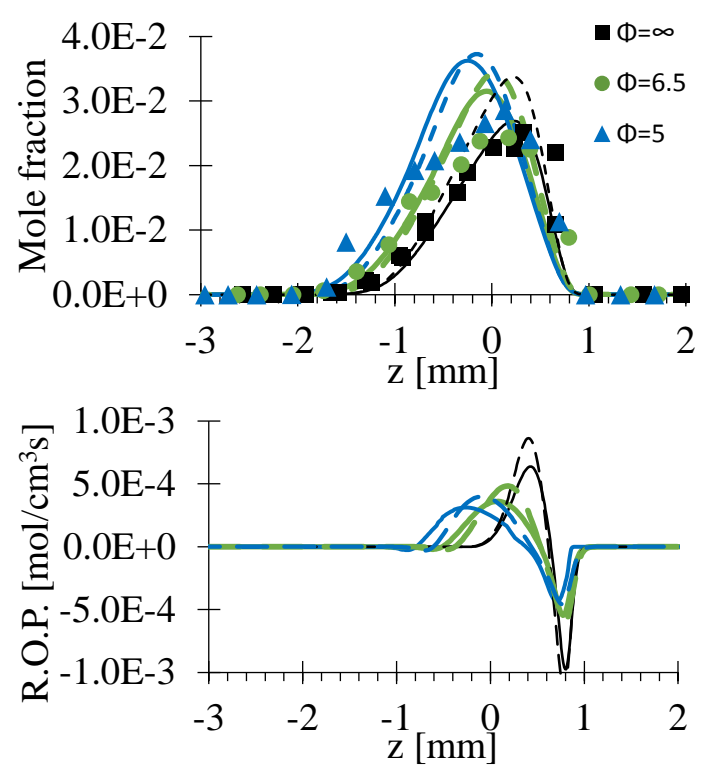

Figure 6: Top: measured (symbols) and computed (lines) mole fractions of $\mathrm{C}_{2} \mathrm{H}_{2}$, versus axial coordinate measured from the GSP. Simulations with USC-II mechanism in solid line and with Pitsch mechanism in dashed line. Bottom: computed volumetric rate of production of $\mathrm{C}_{2} \mathrm{H}_{2}$ versus distance from the GSP with both mechanisms. 

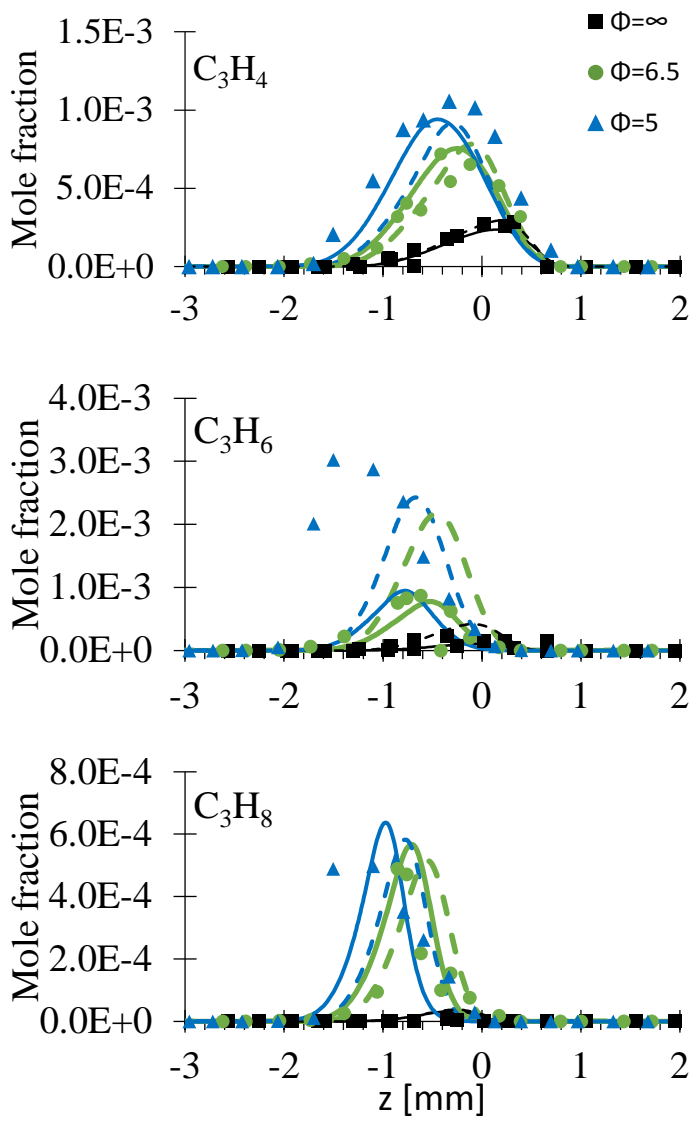

Figure 7: Measured (symbols) and computed (lines) mole fractions of C3s, versus axial coordinate measured from the GSP. Simulations with USC-II mechanism in solid line and with Pitsch mechanism in dashed line. 

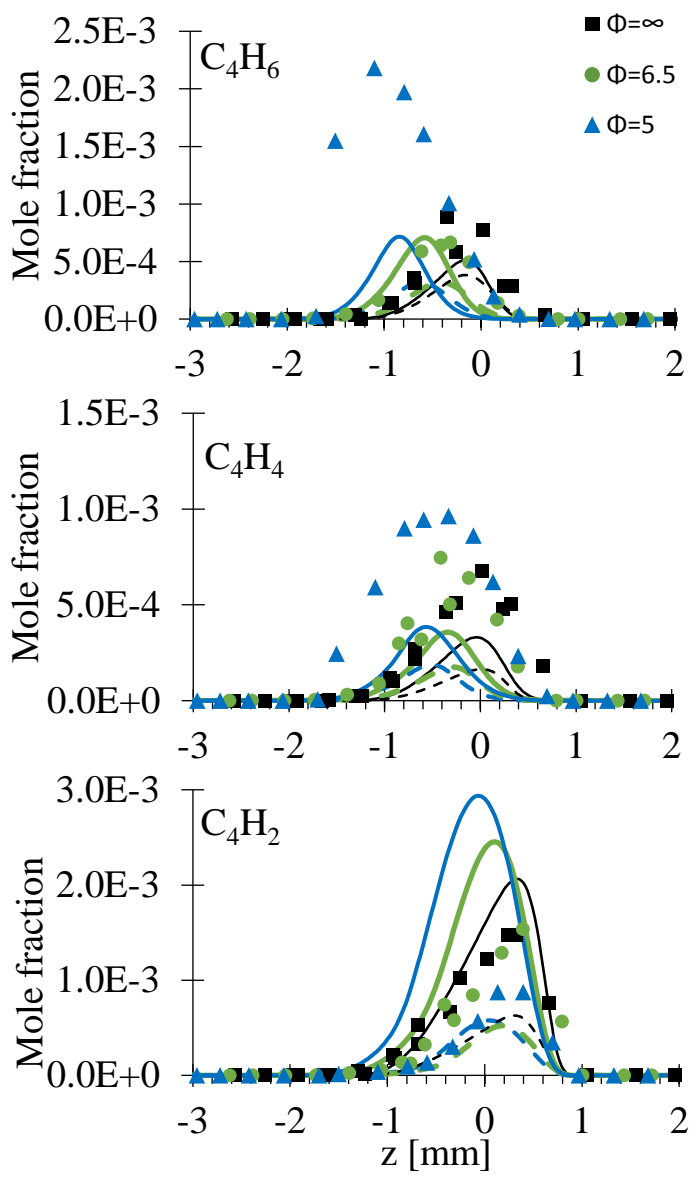

Figure 8: Measured (symbols) and computed (lines) mole fractions of C4s, versus axial coordinate measured from the GSP. Simulations with USC-II mechanism in solid line and with Pitsch mechanism in dashed line. 


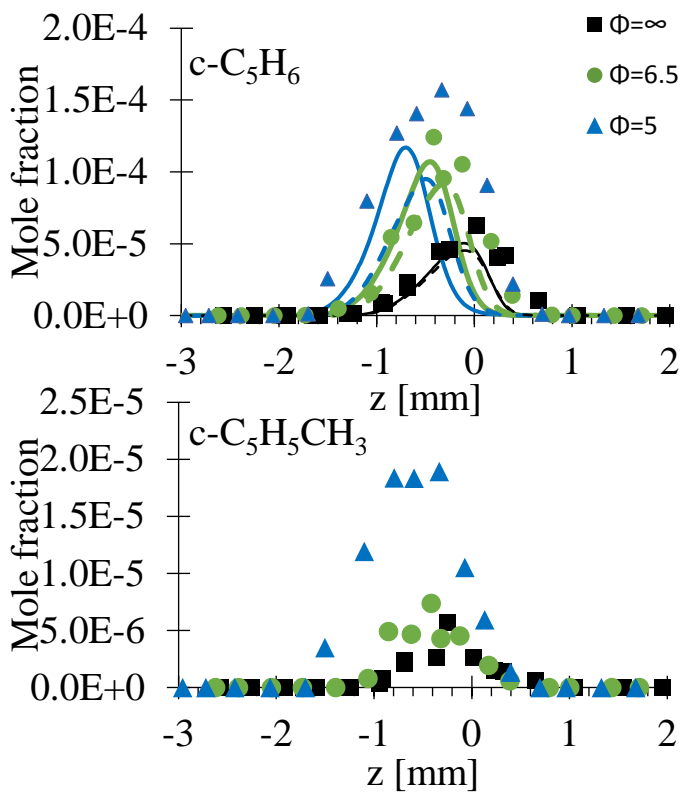

Figure 9: Measured (symbols) and computed (lines) mole fractions of cyclopentadiene and methylcyclopentadiene, versus axial coordinate measured from the GSP. Simulations with USC-II mechanism in solid line and with Pitsch mechanism in dashed line. 


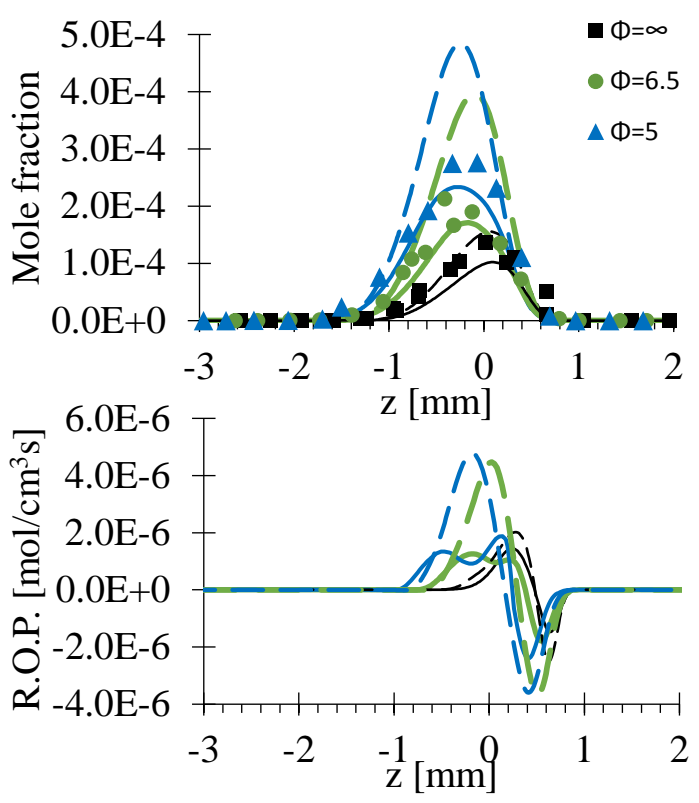

Figure 10: Top: measured (symbols) and computed (lines) mole fractions of $\mathrm{C}_{6} \mathrm{H}_{6}$, versus axial coordinate measured from the GSP. Simulations with USC-II mechanism in solid line and with Pitsch mechanism in dashed line. Bottom: computed volumetric rate of production of $\mathrm{C}_{6} \mathrm{H}_{6}$ versus distance from the GSP with both mechanisms. 


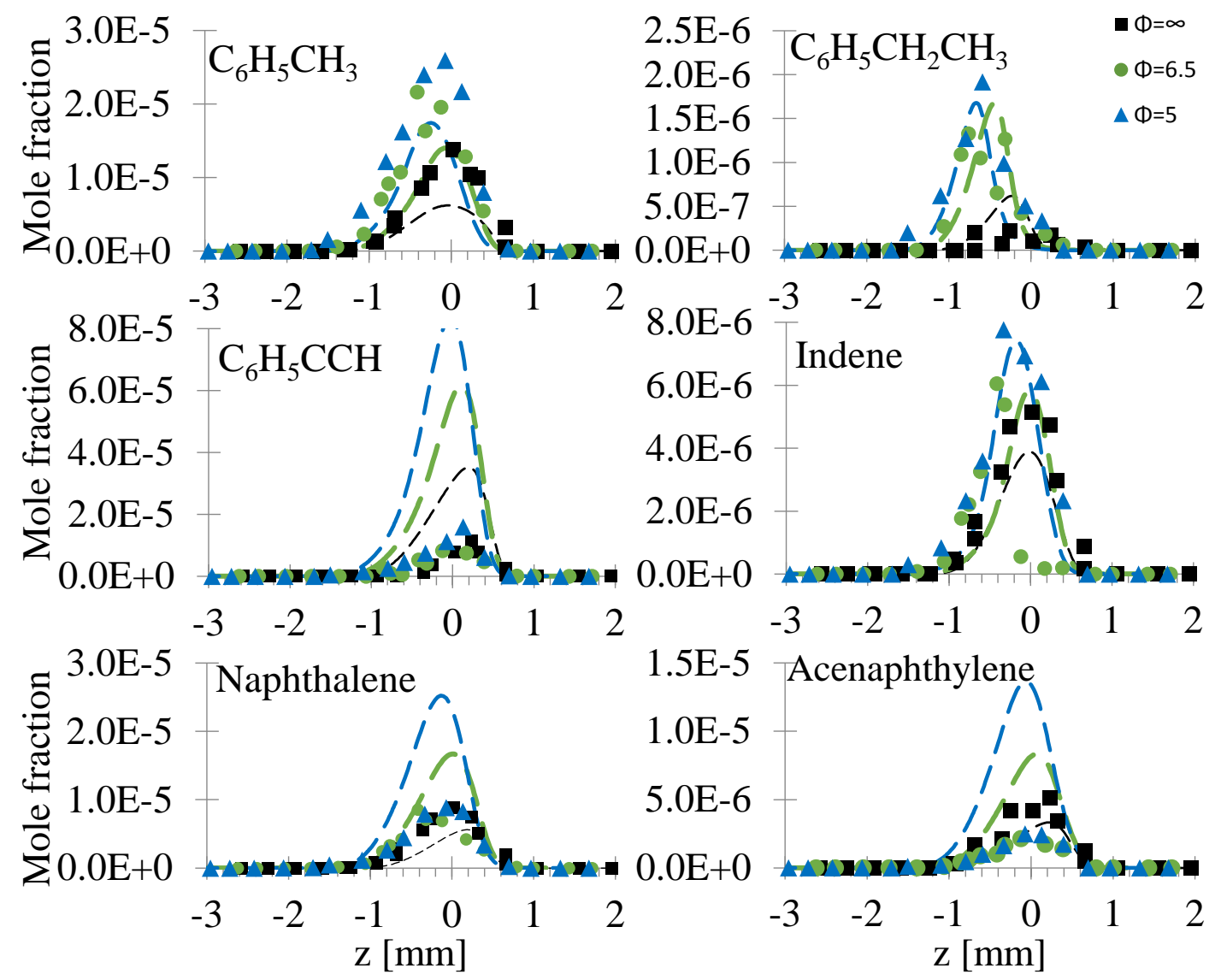

Figure 11: Measured (symbols) and computed (lines) mole fractions of larger (>C6) aromatics versus axial coordinate measured from the GSP. Simulations with Pitsch mechanism only. 

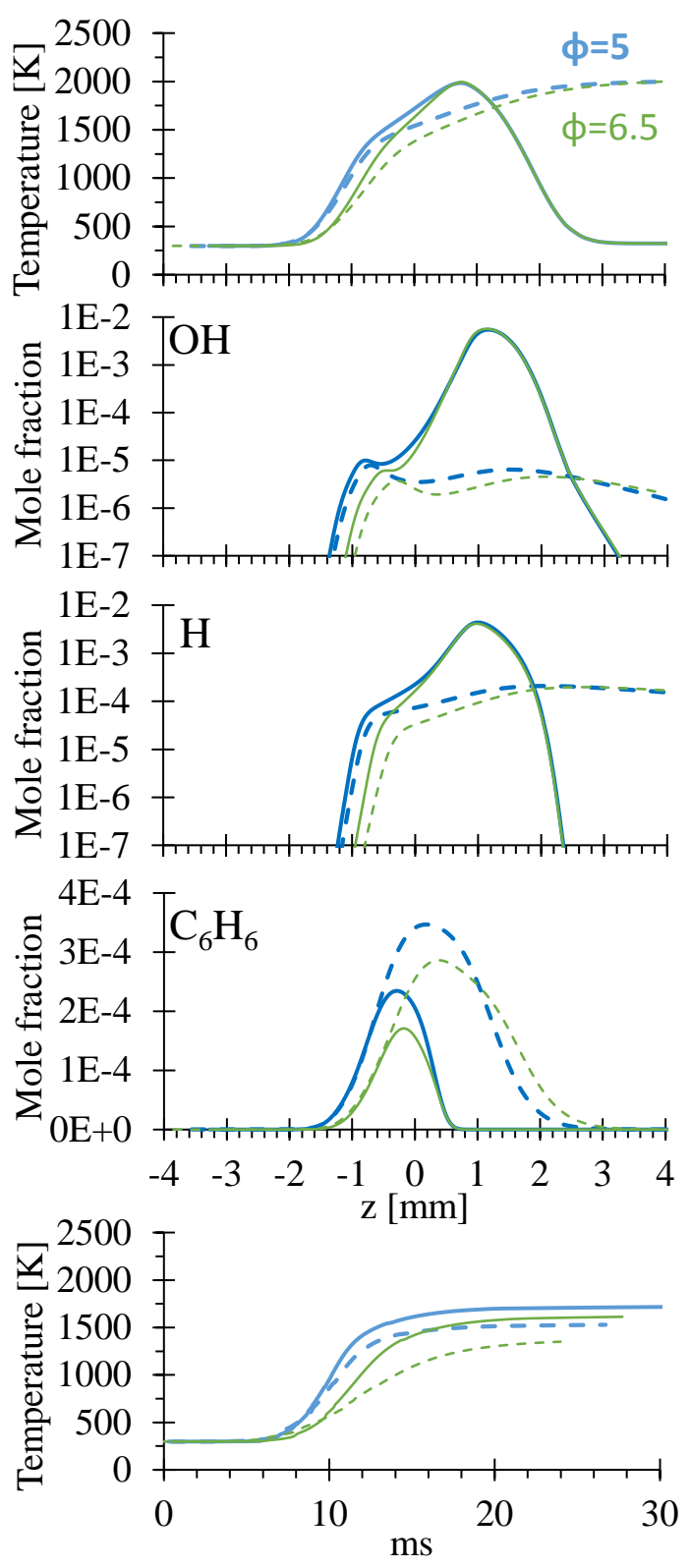

Figure 12: Partially premixed flames compared to the equivalent strained laminar flame stabilized against a hot nitrogen stream. Top to bottom: profiles of temperature, mole fractions of $\mathrm{OH}, \mathrm{H}$ and $\mathrm{C}_{6} \mathrm{H}_{6}$, and temperature-time history. Simulations use the USC- II mechanism. 

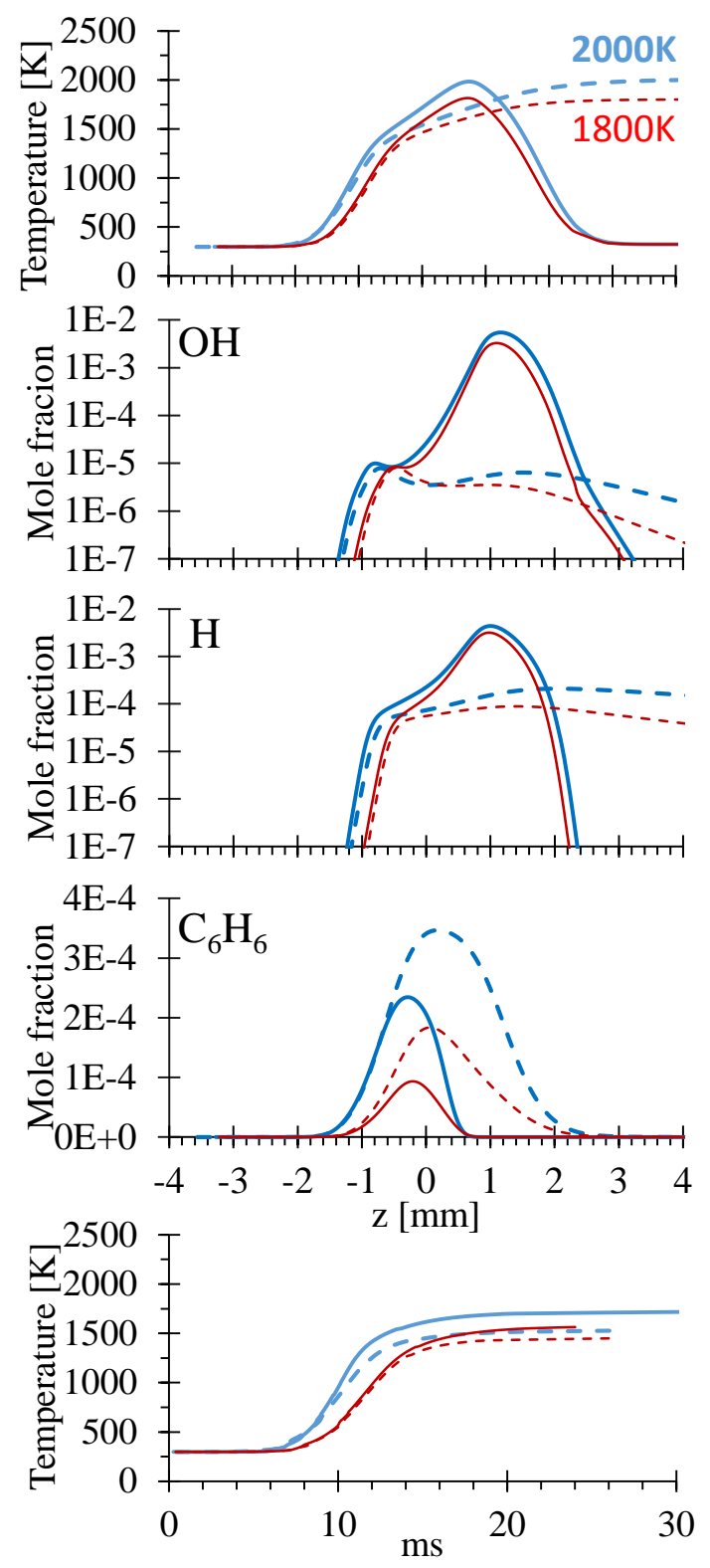

Figure 13: Partially premixed flame (solid line) at $\Phi=5$ compared to the equivalent strained laminar flame (dashed line) stabilized against a hot nitrogen stream at $\mathrm{T}_{\max }=2000 \mathrm{~K}$ (blue lines) and $\mathrm{T}_{\max }=1800 \mathrm{~K}$ (purple lines). Top to bottom: profiles of temperature, mole fractions of $\mathrm{OH}$, $\mathrm{H}$ and $\mathrm{C}_{6} \mathrm{H}_{6}$, and temperature-time history. Simulations use the USC- II mechanism. 


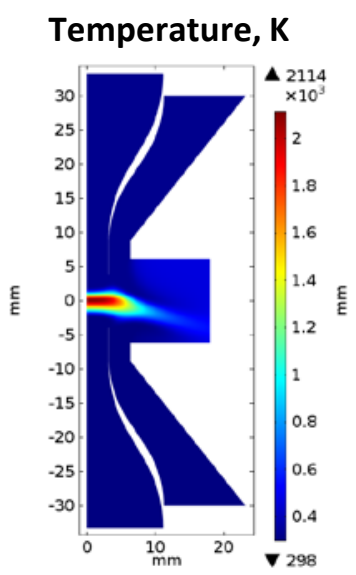

Axial Velocity, $\mathrm{m} / \mathrm{s}$

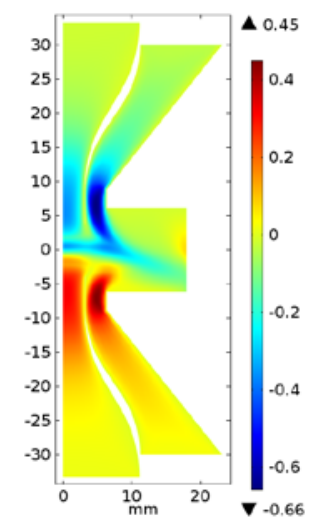

Figure A1: Temperature field (left) and axial velocity field (right) as obtained by 2-D axissymmetric simulation for the purely diffusive $(\Phi=\infty)$ flame. The solution includes the domain between nozzles, the domain inside the burner and the annular region surrounding the burner nozzle outlet. Only half of the domain is shown because of axial symmetry.

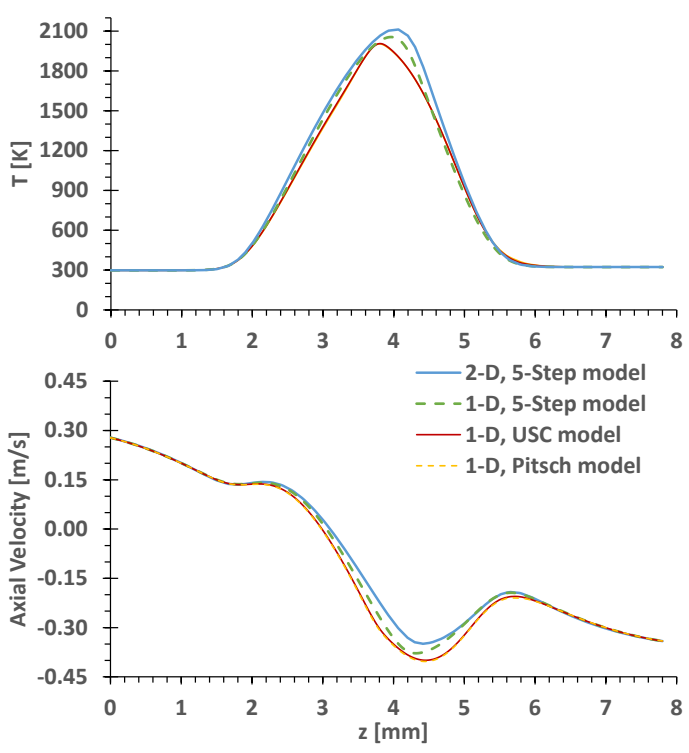

Figure A2: Comparison of temperature profiles (top) and axial velocity profiles (bottom) of the diffusion flame $(\Phi=\infty)$ along the burner axis. Solutions are calculated using the 2-D model with reduced kinetics (blue line) and the one-dimensional OPPDIFF solver using the modified boundary conditions provided by the 2-D model. 
Figure B1: Reaction path analysis of benzene formation with the USC II mechanism in the three investigated flames. Each arrow is labeled with percentage of the production at each step in the pyrolysis process. Species in bold red were detected and quantified by GC-MS analyses. 